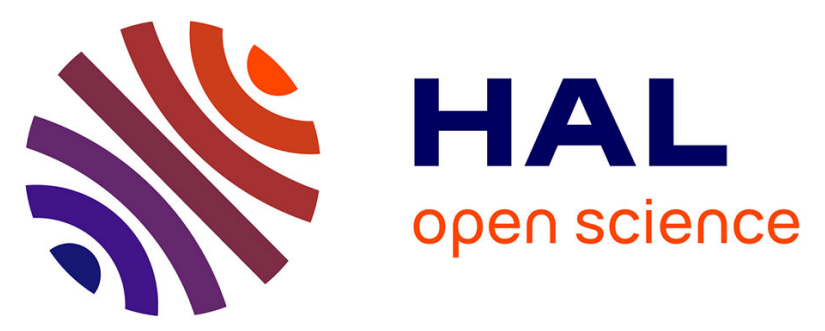

\title{
Using centrifuge tests data to identify the dynamic soil properties: Application to Fontainebleau sand
}

\author{
Zheng Li, Sandra Escoffier, Panagiotis Kotronis
}

\section{To cite this version:}

Zheng Li, Sandra Escoffier, Panagiotis Kotronis. Using centrifuge tests data to identify the dynamic soil properties: Application to Fontainebleau sand. Soil Dynamics and Earthquake Engineering, 2013, 52, pp.77-87. 10.1016/j.soildyn.2013.05.004 . hal-00953641

\section{HAL Id: hal-00953641 \\ https://hal.science/hal-00953641}

Submitted on 15 Nov 2019

HAL is a multi-disciplinary open access archive for the deposit and dissemination of scientific research documents, whether they are published or not. The documents may come from teaching and research institutions in France or abroad, or from public or private research centers.
L'archive ouverte pluridisciplinaire HAL, est destinée au dépôt et à la diffusion de documents scientifiques de niveau recherche, publiés ou non, émanant des établissements d'enseignement et de recherche français ou étrangers, des laboratoires publics ou privés.

\section{다)(1) $(5$}

Distributed under a Creative Commons Attribution - NonCommerciall 4.0 International 


\title{
Using centrifuge tests data to identify the dynamic soil properties: Application to Fontainebleau sand
}

\author{
Zheng $\mathrm{Li}^{\mathrm{a}, \mathrm{b}, *}$, Sandra Escoffier ${ }^{\mathrm{a}}$, Panagiotis Kotronis ${ }^{\mathrm{b}}$ \\ ${ }^{a}$ LUNAM Université, IFSTTAR, GERS, SV, F-44341 Bouguenais, France \\ ${ }^{\mathrm{b}}$ LUNAM Université, Ecole Centrale de Nantes, Université de Nantes, CNRS, Institut de Recherche en Génie Civil et Mécanique (GeM), 1 Rue de la Noë, \\ F-44321 Nantes, France
}

Knowledge of the dynamic properties of the soil is of great importance as the dynamic shear modulus and damping ratio are necessary input data in finite element modeling programs. This paper presents a postprocessing strategy to identify the shear modulus and damping ratio vs. shear strain curves using the experimental results of a dynamic centrifuge program. Application is presented for the Fontainebleau sand. The proposed methodology is fast, robust and able to capture the nonlinear hysteretic behavior of the material. Based on the results, specific parameters for the Fontainebleau sand are identified for the empirical equation of shear modulus and damping ratio proposed by Ishibashi and Zhang [1]. It is found that confining pressure has an important influence on both shear modulus evolution and damping ratio.

\section{Introduction}

Taking into account the dependence of the shear modulus and the damping ratio on the shear strain is crucial in order to apprehend and simulate the cyclic behavior of soils. The accuracy of a numerical simulation largely depends on the quality of the identification of these soil dynamic properties. The calibrated constitutive law should be able to reproduce satisfactorily the monotonic loading back-bone curve and the cyclic (loading-reloading) behavior [2].

Laboratory tests on specimens (triaxial cyclic or resonant column tests) are usually used to estimate the dynamic properties of soils. Centrifuge tests can also be chosen as an alternative solution. Although definitely most costly, they avoid the physical constrains of the laboratory element tests [3], such as boundary conditions due to testing equipment and consolidation conditions. Furthermore, the stress path followed in the centrifuge tests is more realistic.

Several studies concerning the determination of soil properties from experimental stress-strain loops can be found in the literature. Pitilakis et al. [4] compared the results obtained by numerical simulations with the stress-strain loops coming from centrifuge tests (calculated using the method proposed by Zeghal and Elgamal [5]) to verify the soil hysteretic response. Elgamal et al.

\footnotetext{
* Corresponding author at: LUNAM Université, IFSTTAR, GERS, SV, F-44341 Bouguenais, France. Tel.: +33 647467050

E-mail addresses: zheng.li@ifsttar.fr (Z. Li), sandra.escoffier@ifsttar.fr

(S. Escoffier), Panagiotis.Kotronis@ec-nantes.fr (P. Kotronis).
}

[6] studied the dynamic response of a saturated dense sand in a laminated centrifuge container to estimate the shear modulus reduction and the damping ratio and identified a confinement dependence. Brennan et al. [3] reported some key techniques (such as influence of filtering, double integration technique and calculation of shear stress and shear strain) to evaluate the soil properties from dynamic centrifuge tests. Conti and Viggiani [7] proposed analytical expressions for the shear modulus and damping ratio of sand using nonlinear calibration with the experimental data.

This paper presents a series of dynamic free field centrifuge tests on Fontainebleau sand with an embedded earthquake (dynamic loading) simulator [8] and an equivalent shear beam (ESB) container [9,10]. A general methodology is proposed for processing the experimental data avoiding large dispersion and the dependency of the shear modulus and the damping ratio on the shear strain is studied. The specific regression parameters, suitable for Fontainebleau sand, of the unified equation [1] are identified and the influence of the confining pressure on the shear modulus reduction curves is taken into account.

\section{Dynamic centrifuge experimental program}

\subsection{Material properties and centrifuge tests set-up}

Dynamic centrifuge tests were performed to determine the degradation curve of the shear modulus and the damping ratio. The response of a dry sand column to dynamic input signals was 
analyzed. The sand used is of Fontainebleau type with fine grain size and uniform distribution [11]. The sand mass was prepared by air pluviation at $1 g$ gravity level. Its density was controlled to be $80 \%$. Various measured material properties are listed in Table 1.

During the experimental program, two tests (Test-01 and Test-02) were performed corresponding to two different input signals (see Section 2.2). To ensure that the properties of the sand in the tests were the same, in-flight cone penetration testing (CPT) was used. The maximum difference of the two CPT tests is about 5\% which shows good repeatability of the experiments.

All the dynamic centrifuge tests were performed using dry sand under $40 \mathrm{~g}$ level (to avoid confusion in scales and dimensions, all the scales and dimensions in this paper hereafter will be in the prototype scale). Accelerometers were buried into the sand during the air pluviation to measure accelerations at different depths, see Fig. 1. In the middle of the ESB container, a dense vertical array of accelerometers (from channels $\mathrm{CH}-02$ to $\mathrm{CH}-16$ ) was placed to capture the behavior of the soil column and thus to check any possible boundary effect of the container. The vertical distance between each sensor is about $1.2 \mathrm{~m}$ in the prototype scale (i.e. $30 \mathrm{~mm}$ in the model scale). $\mathrm{CH}-29, \mathrm{CH}-31$ and $\mathrm{CH}-32$ are used to verify the displacements from the measured accelerations using double integration.

\subsection{Input signals}

The design of the excitation signals is done considering different signal types, input intensities and frequency contents. First, in order to make the identification process (relatively) easier, simple sinus signals were adopted. Second, signals with different intensities are used in order to be able to identify the shear modulus and damping ratio at different shear strain levels. Finally,

Table 1

Fontainebleau sand NE34: material properties [25].

\begin{tabular}{lllllll}
\hline Soil & $e_{\min }$ & $e_{\max }$ & $e$ & $\nu$ & $D_{r}(\%)$ & $\gamma_{d}\left(\mathrm{kN} / \mathrm{m}^{3}\right)$ \\
\hline Fontainebleau NE34 & 0.545 & 0.866 & 0.520 & 0.25 & 80 & 16.155
\end{tabular}

Notes: e - void ratio (refers to [11]); $\nu$ - poisson ratio; $\gamma_{d}$ - weight of sand; $D_{r}-$ relative density of sand. signals with multiple frequency contents, within the shaker capacity, were selected to study the frequency dependence of the soil response.

The following two input signals were used: (1) a sine input signal with tapered parts (Signal-1), as shown in Fig. 2 and (2) a sine input signal with constant amplitude (Signal-2), as shown in Fig. 3. Two centrifuge tests were performed, and Signal-1 and Signal- 2 were used in Test- 1 and Test- 2 respectively.

The input signal sequences for Test- 1 and Test- 2 are given in Tables 2 and 3. For Test-1, both frequency and amplitude varied. For Test-2 only the amplitude varied. Based on previous experimental campaigns performed at the centrifuge facility, the fundamental frequency of the soil column was estimated approximately equal to $3.5 \mathrm{~Hz}$ in the prototype scale ( $140 \mathrm{~Hz}$ in the model scale). This is why the frequency content of the input waves was set in the range between $2.0 \mathrm{~Hz}$ and $4.5 \mathrm{~Hz}$ (prototype scale).

\section{Experiment data processing-key issues}

It is well known that the over filtering of data causes distortion and can lead to incorrect interpretations [3]. Before applying a filter, it is thus important to know the frequency contents of the input signal in order to appropriately tuned the cut-off frequencies and to remove unwanted noise avoiding over filtering.

Take the $3.5 \mathrm{~Hz}$ input Signal-1 for example (Fig. 4) and its frequency content (Fig. 5). Looking at the frequency representation of the recorded signal it is obvious that during the centrifuge test and due to the non-perfect response of the hydraulic shaker the signal was unavoidably polluted by additional loading frequencies. Signal filtering is thus essential and necessary. One can divide the signal into five parts (beginning, beginning of effective signal, middle of effective signal, ending of effective signal and ending) as shown in Fig. 4. In the following, the Fourier spectrum is plotted for each part separately.

Looking at parts 1 and 5 that have almost the same frequency content, a strong peak exits around $20 \mathrm{~Hz}$ as shown in Fig. 6. This is due to the small mechanical vibrations of the shaker before the arriving of the command signal, called "dither". Since the "dither" signal is regular with small amplitudes and has concentrated frequencies, it has to be taken into account. The cut-off frequencies for parts 1 and 5 are thus set at $10-30 \mathrm{~Hz}$. For parts 2 and 4 ,

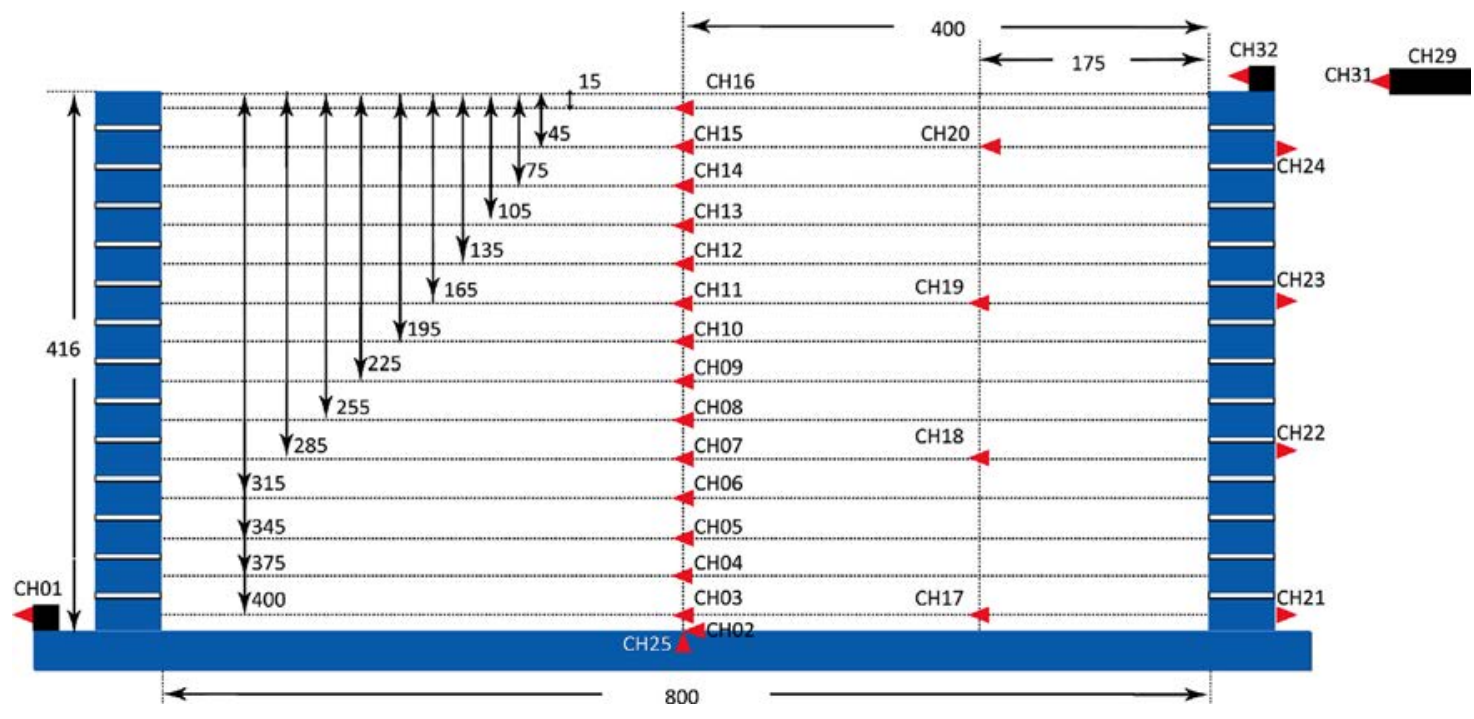

Fig. 1. Dynamic centrifuge tests: experiment set-up.

Note: Dimensions are in $\mathrm{mm}$ (model scale). 


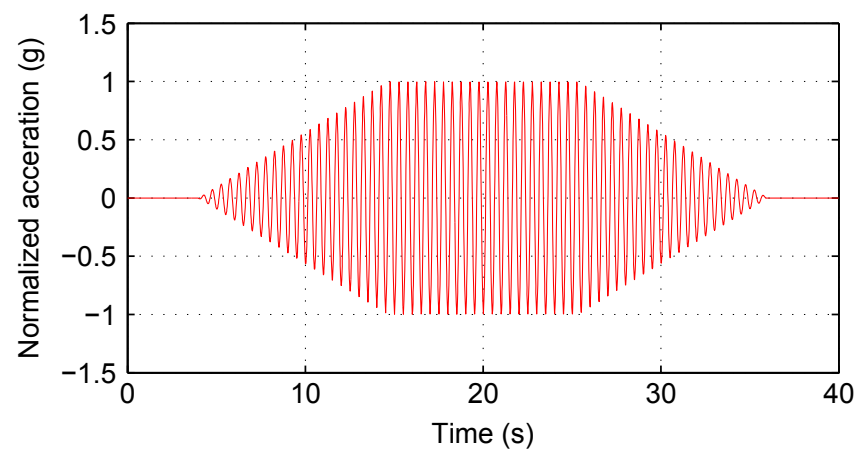

Fig. 2. Dynamic centrifuge test-1: input wave Signal-1 with tapered parts (amplitude normalized).

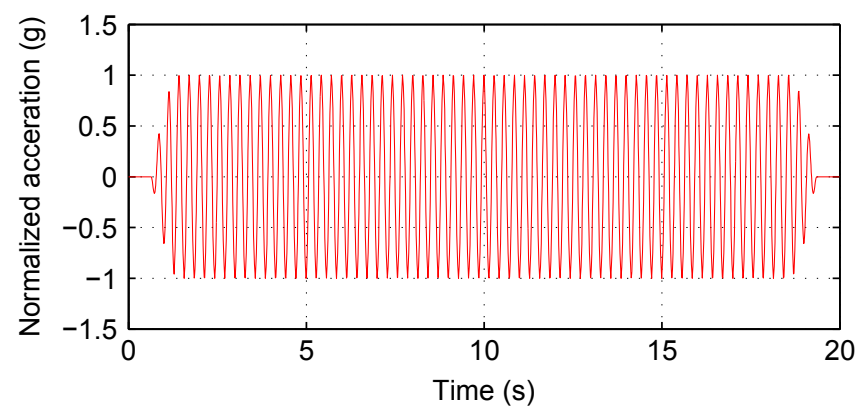

Fig. 3. Dynamic centrifuge test-2: input wave Signal-2 with constant (normalized) amplitude cycles.

Table 2

Test-1: input sequence for Signal-1.

\begin{tabular}{llll}
\hline No. & Signal type & Max. amplitude $(\mathrm{g})$ & Frequency $(\mathrm{Hz})$ \\
\hline 1 & Signal-1 & 0.05 & 2 \\
2 & Signal-1 & 0.05 & 2 \\
3 & Signal-1 & 0.1 & 2 \\
4 & Signal-1 & 0.1 & 2 \\
5 & Signal-1 & 0.2 & 3.5 \\
6 & Signal-1 & 0.2 & 3.5 \\
7 & Signal-1 & 0.2 & 4.5 \\
8 & Signal-1 & 0.2 & 4.5 \\
9 & Signal-1 & 0.4 & 4.5 \\
10 & Signal-1 & 0.4 & 4.5 \\
\hline
\end{tabular}

Note: Signal-1 is the sine signal with tapered parts.

Table 3

Test-2: Input sequence for Signal-2.

\begin{tabular}{llll}
\hline No. & Signal type & Max. amplitude $(\mathrm{g})$ & Frequency $(\mathrm{Hz})$ \\
\hline 1 & Signal-2 & 0.05 & 3.5 \\
2 & Signal-2 & 0.05 & 3.5 \\
3 & Signal-2 & 0.1 & 3.5 \\
4 & Signal-2 & 0.1 & 3.5 \\
5 & Signal-2 & 0.2 & 3.5 \\
6 & Signal-2 & 0.2 & 3.5 \\
7 & Signal-2 & 0.4 & 3.5 \\
8 & Signal-2 & 0.4 & 3.5 \\
\hline
\end{tabular}

Note: Signal-2 is the sine signal with constant amplitude.

the influence of the higher harmonic frequencies cannot be ignored, see Fig. 7. These frequencies are part of the input signal, although unexpected, and can modify the total response. The cutoff frequencies are set at $0.5-30 \mathrm{~Hz}$. In a similar way, the cut-off frequencies for part 3 (Fig. 8) are set at $0.5-25 \mathrm{~Hz}$. As a final

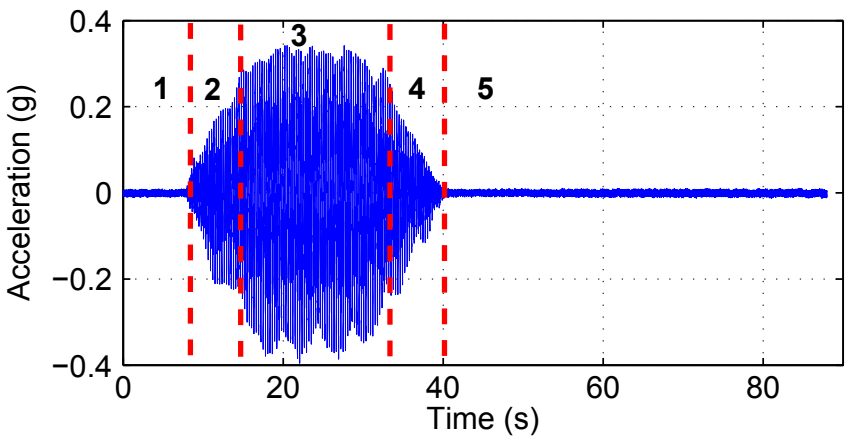

Fig. 4. Signal-1: time vs. acceleration.

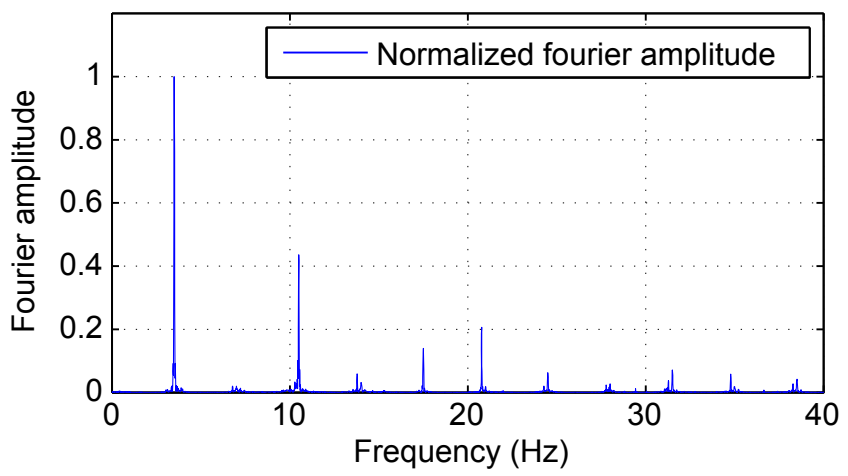

Fig. 5. Signal-1: Fourier spectrum.

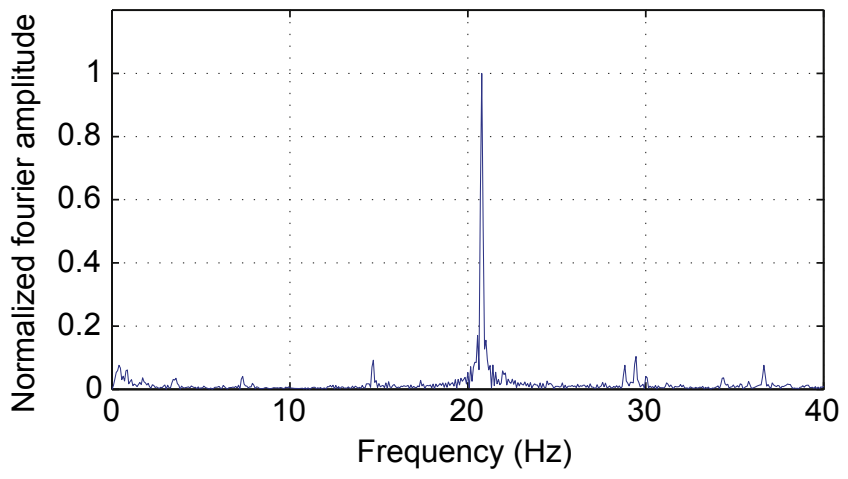

Fig. 6. Signal-1: Fourier spectrum - parts 1 and 5 .

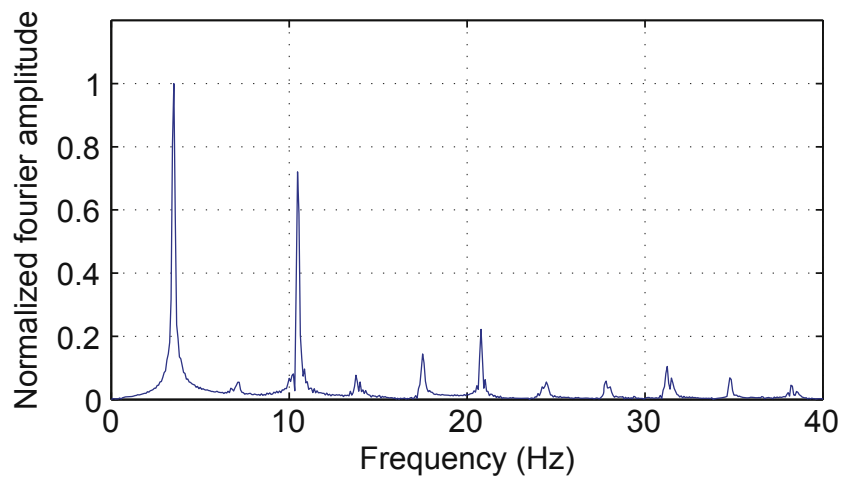

Fig. 7. Signal-1: Fourier spectrum - parts 2 and 4.

remark, for the five parts of the initial signal presented above, the starting and ending points should be chosen close to 0 in order to avoid or minimize the boundary distortion. This technique was applied to all the signals processed in this paper. 


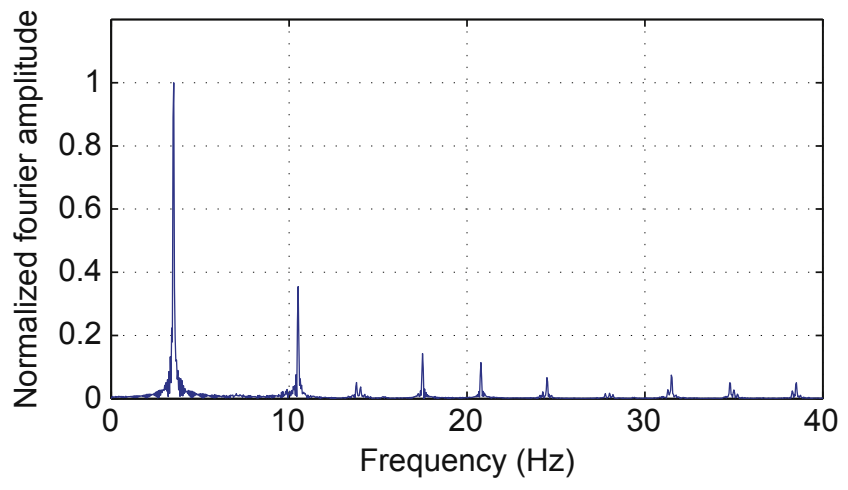

Fig. 8. Signal-1: Fourier spectrum - part 3.

\section{Shear modulus}

\subsection{Maximum shear modulus profile}

The maximum shear modulus $G_{\max }$ profile at small-strain level is a key parameter for geotechnical problems. Different studies have shown that for fine grained sand, the $G_{\max }$ profile depends on the void ratio and the effective confining pressure [12-14]. The following formula proposed by Hardin and Drnevich [15] is often used to estimate the $G_{\max }$ profile:

$G_{\max }=A \cdot \frac{(B-e)^{2}}{(1+e)} \cdot \sigma_{\mathrm{c}}^{C}$

where $G_{\max }$ is in MPa, $e$ the void ratio ( 0.52 for the Fontainebleau sand at relative density $80 \%$ ) and $\sigma_{\mathrm{c}}$ the confining pressure. A, B and $C$ are constants taken as 200, 2.17 and 0.47 respectively (Delfosse-Riday et al. [11]). The confining pressure $\sigma_{\mathrm{c}}$ is calculated by

$\sigma_{\mathrm{c}}=\frac{\left(1+2 K_{0}\right) \gamma_{\mathrm{d}} z}{3}$

$z$ being the depth and $\gamma_{\mathrm{d}}$ the weight of the sand. $K_{0}$ expresses the lateral soil pressure coefficient exerted by the soil at rest. The general form of $K_{0}$ is

$K_{0}=\frac{\nu}{1-\nu}$

where $\nu$ is the Poisson ratio of the sand. For the specific case of centrifuge physical modeling, Gaudin [16] proposed the following equation to determine $K_{0}$ (with $D_{\mathrm{r}}$ the relative density of the sand, see Table 1 ):

$K_{0}=-\frac{1}{2.9} D_{\mathrm{r}}+0.63$

In our case, the values obtained from Eqs. (3) and (4) are 0.333 and 0.354 respectively. In the following, $K_{0}$ is taken equal to 0.354 .

Another way to calculate the $G_{\max }$ profile is to use the shear wave velocity at different soil layers. In dynamic centrifuge experiments, the shear wave velocity profile can be calculated by determination of the time delay (cross-correlation) of the signals between pairs of accelerometers. In order to be certain that the shear wave velocity corresponds to a small-strain level (i.e. the sand being in the elastic or in the nearly elastic range), only the experimental data from low intensity exciting signals are adopted hereafter. During the experimental campaign, two low intensity signals were introduced (the sine signal input $2 g-80 \mathrm{~Hz}$ and the sine signal input $2 g-140 \mathrm{~Hz}$ ). Since the natural frequency of the sand column is approximately $3.5 \mathrm{~Hz}$ in the prototype scale ( $140 \mathrm{~Hz}$ in the model scale), only the data from the $2 g-80 \mathrm{~Hz}$ signal are used hereafter to calculate the shear wave velocity to avoid possible nonlinear responses due to amplification phenomena.

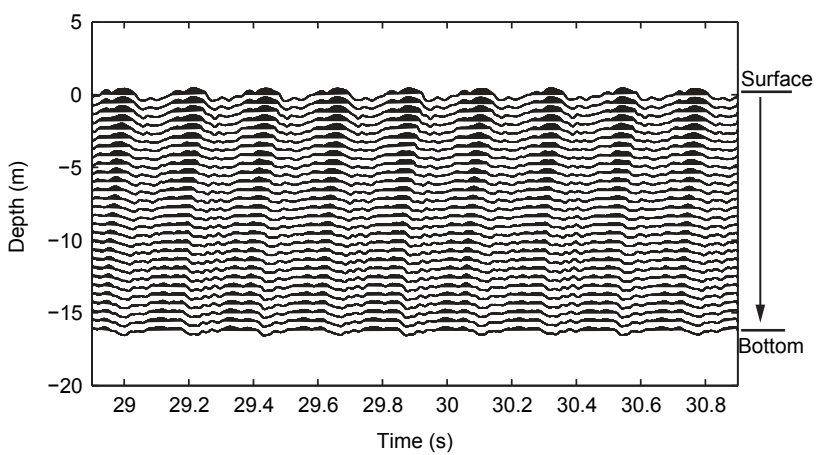

Fig. 9. Dynamic centrifuge tests: seismogram of the input signal sine $2 g-80 \mathrm{~Hz}$.

The strain level is estimated to be about $6.16 \times 10^{-3} \%$ (calculated by double integration). The qualitative representation of the signal delay is shown in Fig. 9.

Based on the signal delay (computed by cross-correlation) between the soil layers, the shear wave velocity is calculated and the shear modulus profile can be determined from the following equation:

$G_{\max }=\rho V_{s}^{2}$

where $\rho$ and $V_{\mathrm{s}}$ are the density of the soil and the shear wave velocity respectively.

The shear wave velocity for depths $0 \sim-6 \mathrm{~m},-6 \sim-12 \mathrm{~m}$ and $-12 \sim-16 \mathrm{~m}$ are respectively calculated as $205.7 \mathrm{~m} / \mathrm{s}, 246.0 \mathrm{~m} / \mathrm{s}$ and $311.8 \mathrm{~m} / \mathrm{s}$. The maximum shear modulus profiles are calculated using Eqs. (1) and (5) and the results are compared in Fig. 10. According to Brennan et al. [3], using the signal delay between accelerometers is less accurate. Nevertheless it provides an alternative way to verify the distribution of shear modulus vs. depth. The comparison of the results provided by Eqs. (1) and (5) can thus be only qualitative, however the two curves follow the same trend and show significant correlation.

\subsection{Shear modulus evolution}

\subsubsection{Shear stresses}

In centrifuge tests, shear stresses can be calculated indirectly using the accelerometers measurements $[3,5]$ according to the following equation:

$\tau(z)=\int_{0}^{z} \rho \ddot{u} \mathrm{~d} z$

where $\tau$ is the shear stress at depth $z$ and $\ddot{u}$ the absolute acceleration. It is obvious that the accuracy of the calculation depends on the acceleration profile. Thanks to the large number of accelerometers placed in the tests (see Fig. 1), detailed acceleration profiles can be obtained by fitting the acceleration data points as shown in Fig. 11. Using a simple Newton-Cotes formula for the numerical integration (e.g. trapezoidal integration) the shear stresses can thus be obtained. Results are shown in Fig. 11 for a specific time $t$ (Test-01, input signal with tapered parts $(0.2 \mathrm{~g}$ $3.5 \mathrm{~Hz}$ )). The trend of the acceleration profile is shown by a spline fitted curve.

\subsubsection{Shear strains}

Double integration is used to calculate shear strains in the different soil layers, a procedure that is also necessary to avoid drifting of the results [3]. $\mathrm{CH}-29$ (Fig. 1) is a laser sensor that measured the distance between the two black blocks. $\mathrm{CH}-31$ and $\mathrm{CH}-32$ are two accelerometers that can be used to measure the same distance. The comparison for the Signal-1 is shown in Fig. 12 (a similar comparison was also performed for the Signal-2). 
The good agreement of the comparison indicates the validation of the adopted double integration process. By applying a doubleintegration process on the discrete acceleration data, the displacement $u_{\mathrm{i}}$ at each sand layer $z_{\mathrm{i}}$ can be calculated. Zeghal and Elgamal [5] used an average shear strain equation to study data from earthquake records based on the first order derivative with respect to depth. In this paper, due to the important numbers of accelerometers used in the experiment, higher order formulas are applied for the calculation of the shear strains: first order (Eq. (7)), second order (Eq. (8)) and fourth order (Eq. (9)) respectively

$\gamma_{\mathrm{i}}=\frac{u_{\mathrm{i}}-u_{\mathrm{i}+1}}{h}$

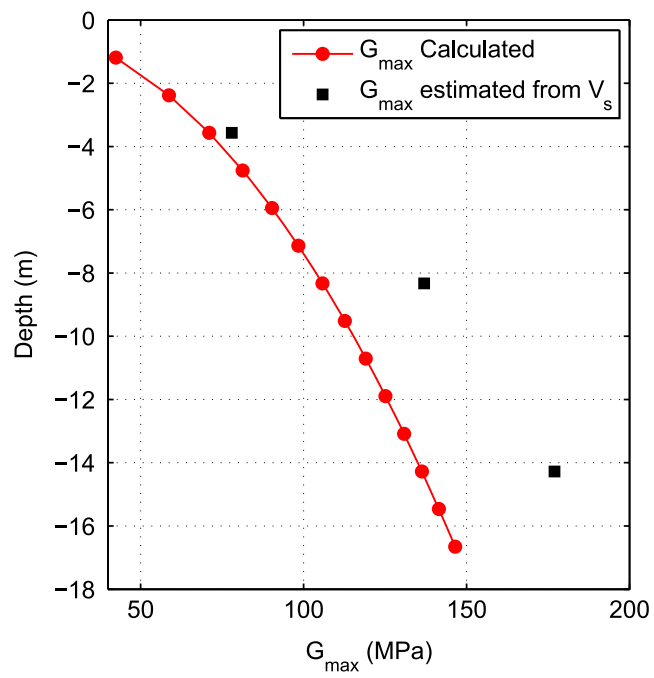

Fig. 10. $G_{\max }$ profiles using Eqs. (1) and (5).

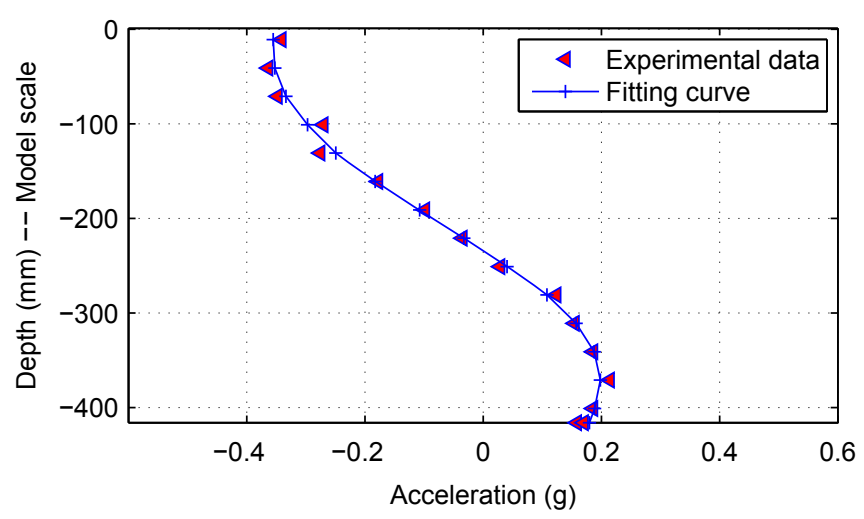

Fig. 11. Acceleration profiles at specific time $t$.

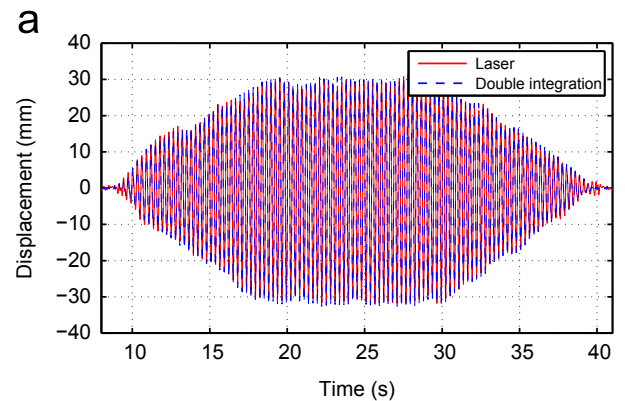

$\gamma_{\mathrm{i}}=\frac{u_{\mathrm{i}-1}-u_{\mathrm{i}+1}}{2 h}$

$\gamma_{\mathrm{i}}=\frac{-u_{\mathrm{i}-2}+8 u_{\mathrm{i}-1}-8 u_{\mathrm{i}+1}+u_{\mathrm{i}+2}}{12 \mathrm{~h}}$

Note that when using the fourth order formula, four accelerometers are necessary. At the bottom or near the top of the ESB container only the first or second order formulas have thus been used.

A schematic representation of the calculated shear strains is shown in Fig. 13. It is obvious that when using the first order formula, the shear strain profile is not continuous. For higher order formulas however, smoother, more realistic profiles are obtained.

\subsubsection{Shear stress vs. shear strain loops}

The typical responses of the Fontainebleau sand in terms of hysteresis loops (shear stress vs. shear strain) at different depths are shown in Fig. 14 (Test-2, input signal with constant amplitude, $0.4 \mathrm{~g}, 3.5 \mathrm{~Hz}$ ). The shear strain level at the top layers is $0.55 \%$ while at the bottom layer is about $0.05 \%$. Compared to the small shear strain level $\left(6.16 \times 10^{-3} \%\right)$ used to estimate the shear wave velocity in the previous section, it is evident that important nonlinearities are developed at different depths and different confining pressures (especially at the top layers). Almost all the loops are well centered, which makes easier the identification of the hysteretic response of the sand. It is also observed, qualitatively, that the slope of the loop axis increases with increasing confining pressure.

\subsubsection{A post-processing strategy to quantify the variation of the} shear modulus with respect to the shear strain

Quantifying the degradation of the shear modulus with respect to the shear strain and thus for the whole range of loading is not an easy task since the experimental data are often distorted and polluted by noise (e.g. background white noise or high frequencies). This is particularly true in the small strain range $\left(1 \times 10^{-4_{\%}} \% \sim 3 \times 10^{-3_{\%}} \%\right)$, as shown in Fig. 15(a) (depth $1.2 \mathrm{~m}$ with confining pressure $11 \mathrm{kPa})$. The distorted hysteresis loops make impossible to read the "correct" shear modulus (or the damping ratio, see Section 5) [3].

A post-processing strategy is proposed hereafter to quantify the variation of the shear modulus with respect to the shear strain. The main ideas are:

- It is observed that when putting together several distorted hysteresis loops, the new group tends to be more "smooth" and representative of the soil behavior. For example, in Fig. 15 the grouped hysteresis loops indicate a linear behavior for a small strain level around $\pm 2.5 \times 10^{-3} \%$. One should thus select adequately a group of hysteresis loops corresponding to the same shear strain level.

- For a complete centrifuge test, different groups of hysteresis loops corresponding to the same shear strain levels should be carefully chosen. For each group, the corresponding average

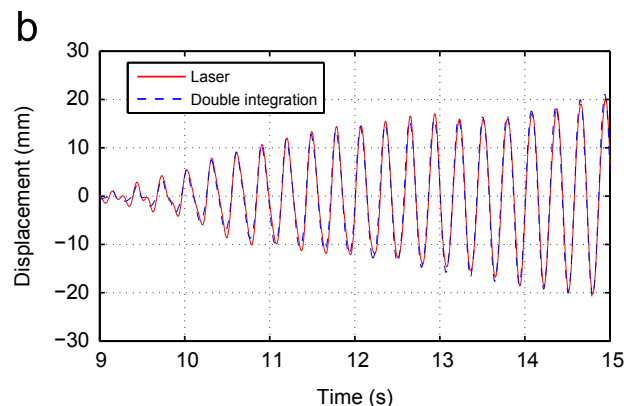

Fig. 12. Verification of the double-integration procedure: comparison of the results using double-integration and the laser sensor (a) and zoom view (b). 
loop can be found and used to calculate the shear modulus (or the damping ratio, see Section 5).

- The method to find the average loop is illustrated in Fig. 16. Each group of loops is divided into two parts using a cutting plane (in Fig. 16, see the double dash line connecting the two

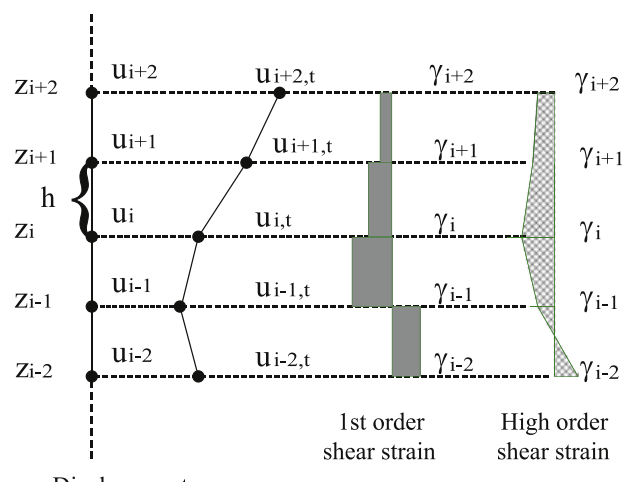

Fig. 13. Shear strain profiles using different order formulas.
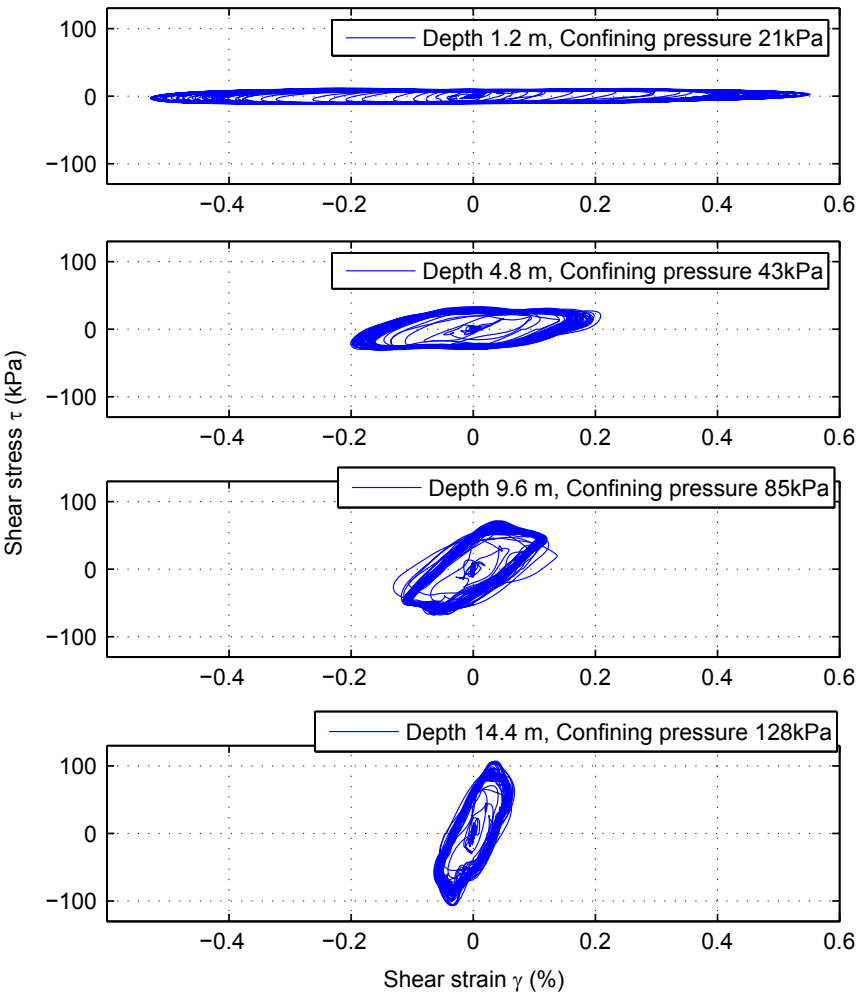

Fig. 14. Dynamic centrifuge tests: shear stress vs. shear strain loops at different depths. points with maximum distances from the center of the loops). For the upper and the lower part, the mean values at different cross-sections $(S 1, S 2, \ldots, S n)$ can be found. The average loop is the one passing through all the mean values points.

The proposed strategy is applied hereafter to the whole range of the dynamic centrifuge experimental data. As shown in Fig. 17(a)-(e) the method captures the average behavior for all the different loading steps. In Fig. 17(a), corresponding to a small shear strain level, the average loop is characteristic of an (almost) linear response. The nonlinear behavior is obvious in Fig. 17(b)-(e) when looking at the size of the hysteresis loops. The proposed method gives satisfactory results even for complicated patterns (see Fig. 17(d)). If just one single loop exists, the average loop reduces to this single loop. Furthermore, even if this single loop is open, the average loop is closed (see Fig. 17(f)).

The final step is to calculate the equivalent shear modulus (Fig. 18) according to the following equation:

$G=\frac{\tau_{\max }-\tau_{\min }}{\gamma_{\max }-\gamma_{\min }}$

Applying the previous procedure to the experimental data coming from the two different sine inputs (Figs. 2 and 3 ) the shear modulus is calculated hereafter. In Fig. 19 (depth of $1.8 \mathrm{~m}$ ), one can see that results are similar for the two input loadings. This was also verified at different depths of the container, see Fig. 20 (depth of $5.4 \mathrm{~m}$ ). It also proves that the response of the sand is, as often quoted in the literature [14,17-19], hysteretic and frequency independent. Since the tapered signal can provide a more smoothed variation of shear strain, the results from sine input with tapered signal (blue round points) are more consistent and continuous than that from the sine input with constant amplitude (red squares), see in Figs. 19 and 20.

In the following, the data coming from the two sine inputs are merged in order to have a relative large database of the sand response.

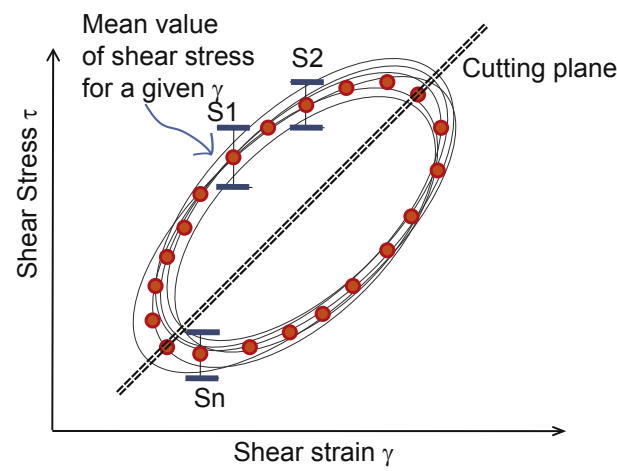

Fig. 16. The method to find the average loop.

b

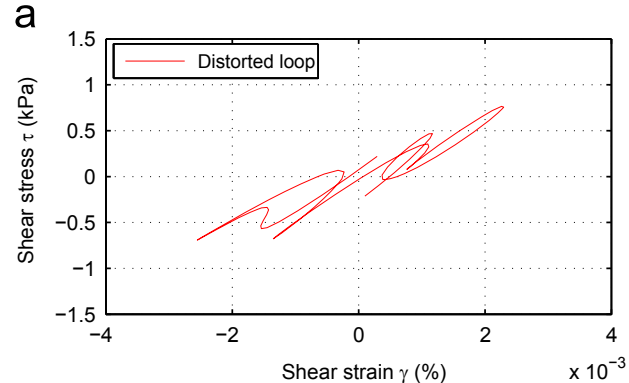

Fig. 15. Dynamic centrifuge tests: distorted hysteresis loop (a) and group of distorted hysteresis loops (b). 

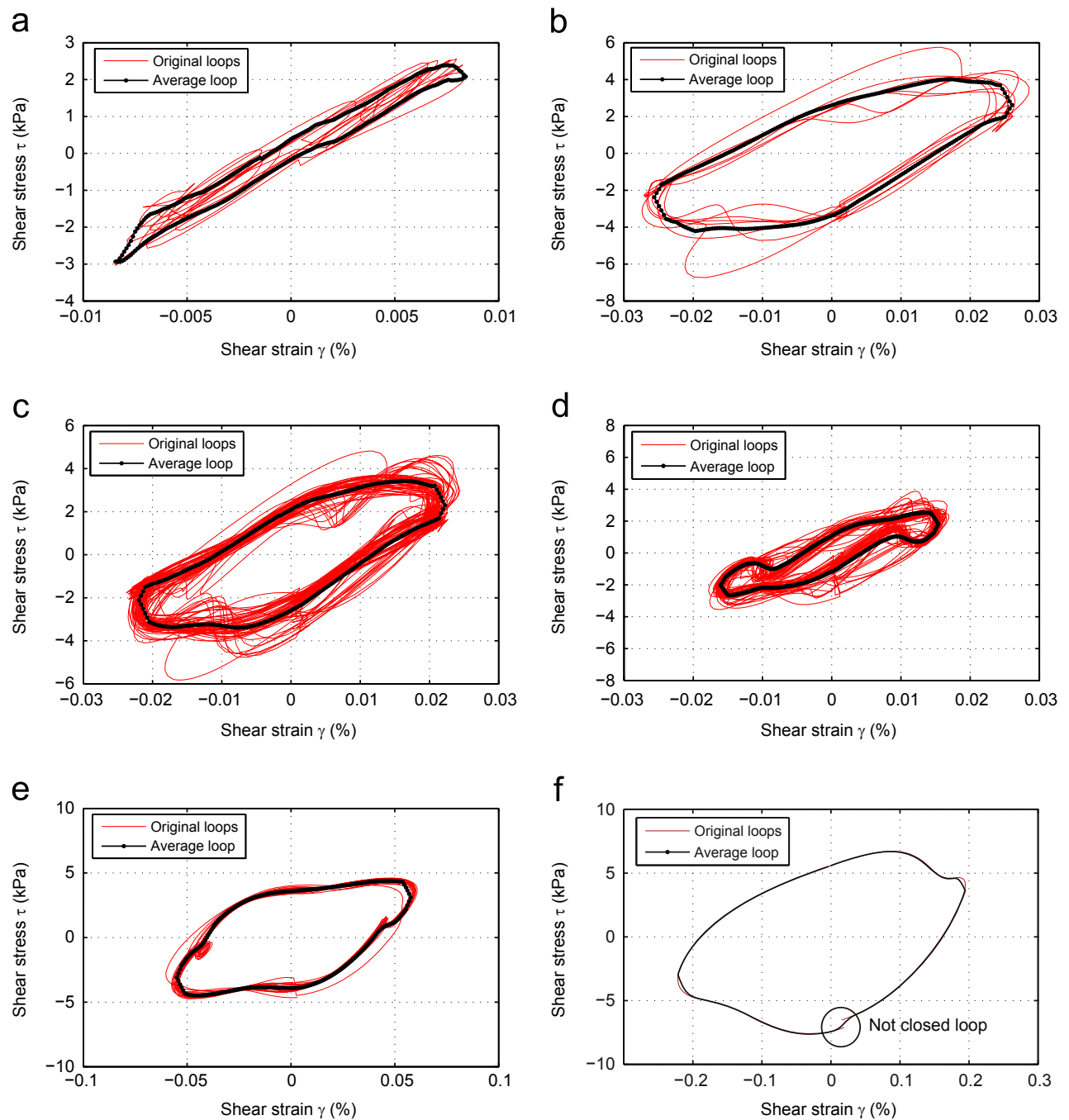

Fig. 17. Dynamic centrifuge tests: calculating the average loop at different depths: (a) $0.6 \mathrm{~m}$ (confining pressure $11 \mathrm{kPa}$ ); (b) $1.2 \mathrm{~m}$ (confining pressure $43 \mathrm{kPa}$ ); (c) $4.8 \mathrm{~m}$ (confining pressure $75 \mathrm{kPa}$ ); (d) $9.6 \mathrm{~m}$ (confining pressure $96 \mathrm{kPa}$ ); (e) $14.4 \mathrm{~m}$ (confining pressure $117 \mathrm{kPa}$ ); (f) $16.0 \mathrm{~m}$ (confining pressure $149 \mathrm{kPa}$ ).

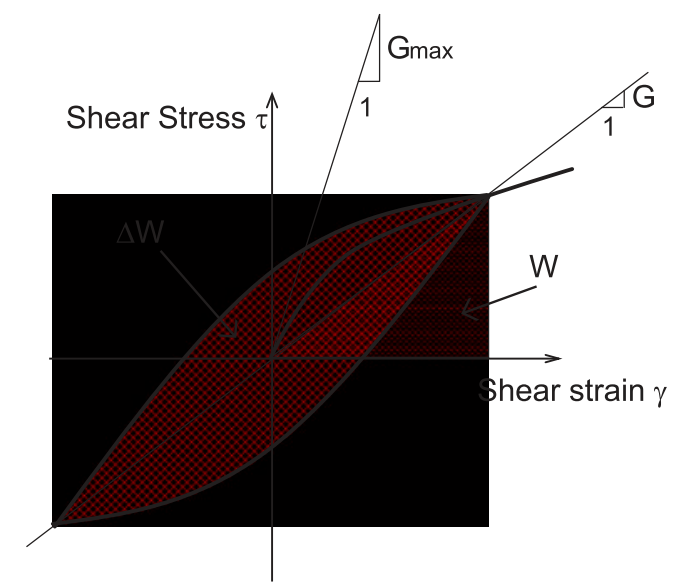

Fig. 18. Equivalent shear modulus $(G)$, elastic stored strain energy $(W)$ and dissipation energy $(\Delta W)$.

\subsubsection{Empirical equation}

The evolutions of the soil shear modulus and shear strain during a cyclic are mainly controlled by the confining pressure and the soil plastic index. The effect of the confining pressure has been studied by Hardin et al. [20] and Iwasaki et al. [14]. Kokusho [21]

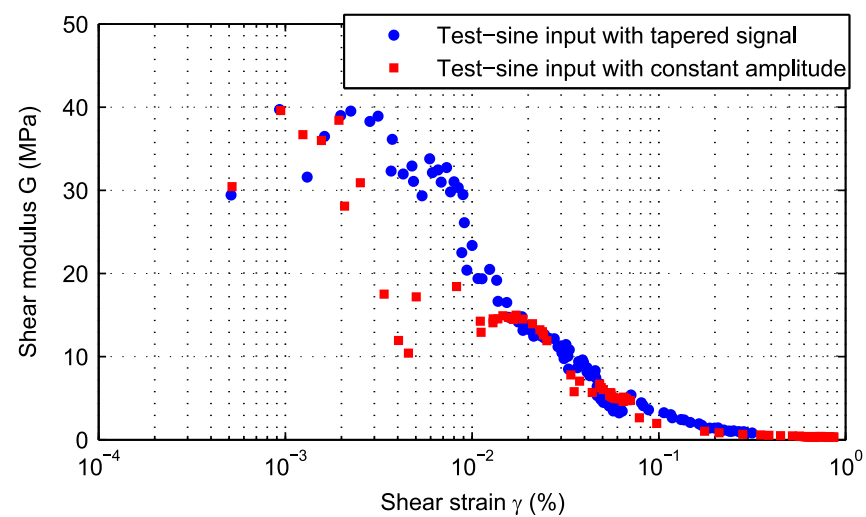

Fig. 19. Dynamic centrifuge tests: shear modulus vs. shear strain of the Fontainebleau sand layer at depth $1.8 \mathrm{~m}$ (confining pressure $21 \mathrm{kPa}$ ) - two types of loading signal. (For interpretation of the references to color in this figure caption, the reader is referred to the web version of this article.)

and Ishibashi [22] have found that its effect is more pronounced for soils with a low plasticity index. Ishibashi and Zhang [1] have proposed an empirical equation linking the maximum shear modulus $G_{\max }$, the confining pressure $\sigma_{c}$, the shear strain $\gamma$, the plastic index PI and two parameters $K(\gamma)$ and $m(\gamma)-m_{0}$ that control the evolution of the shear modulus. Specific values of these 


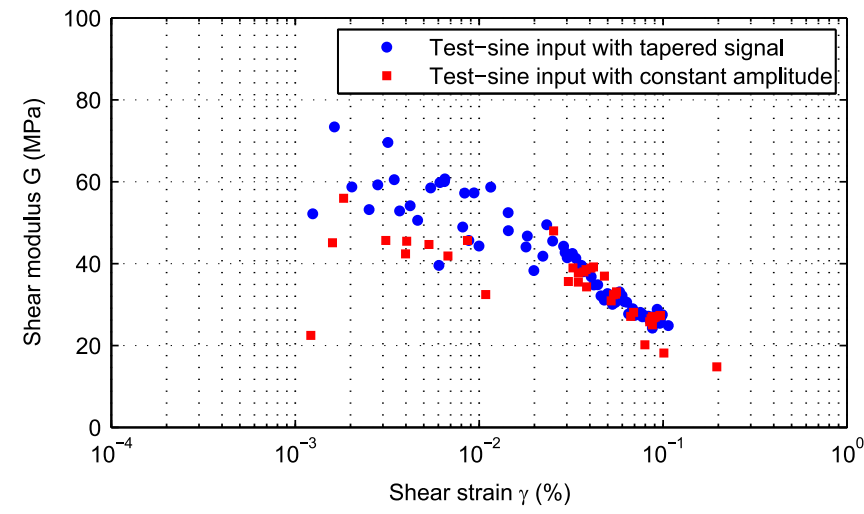

Fig. 20. Dynamic centrifuge tests: shear modulus vs. shear strain of the Fontainebleau sand layer at depth $5.4 \mathrm{~m}$ (confining pressure $53 \mathrm{kPa}$ )—two types of loading signal. (For interpretation of the references to color in this figure caption, the reader is referred to the web version of this article.) parameters (computed by nonlinear regression) for the Fontainebleau sand are proposed hereafter, fitted with the dynamic centrifuge experimental data.

Since dry Fontainebleau sand was used in the experimental campaign was dry, the plastic index is taken equal to $P I=0$. The empirical equation takes the following simplified form $(\gamma$ in $(\mathrm{m} / \mathrm{m})$ and $\sigma_{c}$ in $\left.(\mathrm{kPa})\right)$ :

$$
\frac{G}{G_{\max }}=K(\gamma) \sigma_{\mathrm{c}}^{m(\gamma)-m_{0}}
$$

$K(\gamma)$ and $m(\gamma)-m_{0}$ are tuned to fit the dynamic centrifuge experiment data and are calculated according to Eqs. (12) and (13). The comparison of the empirical equation results and the experimental data at different depths (confining pressures) is presented in Fig. 21:

$K(\gamma)=0.5\left[1+\tanh \left\{\ln \left(\frac{0.000102}{\gamma}\right)^{0.613}\right\}\right]$

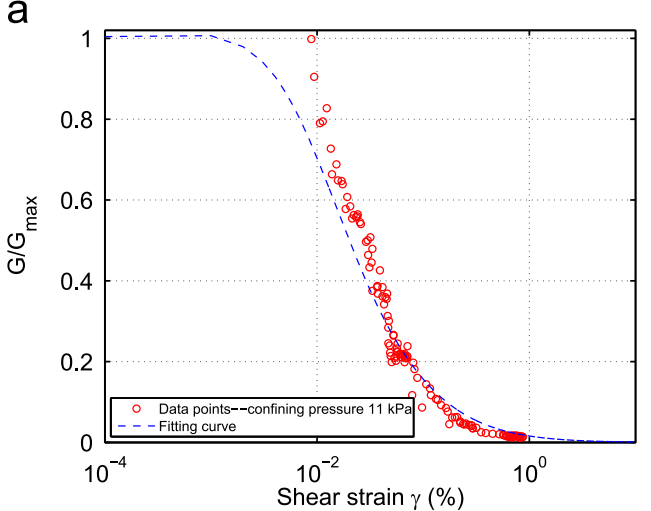

b
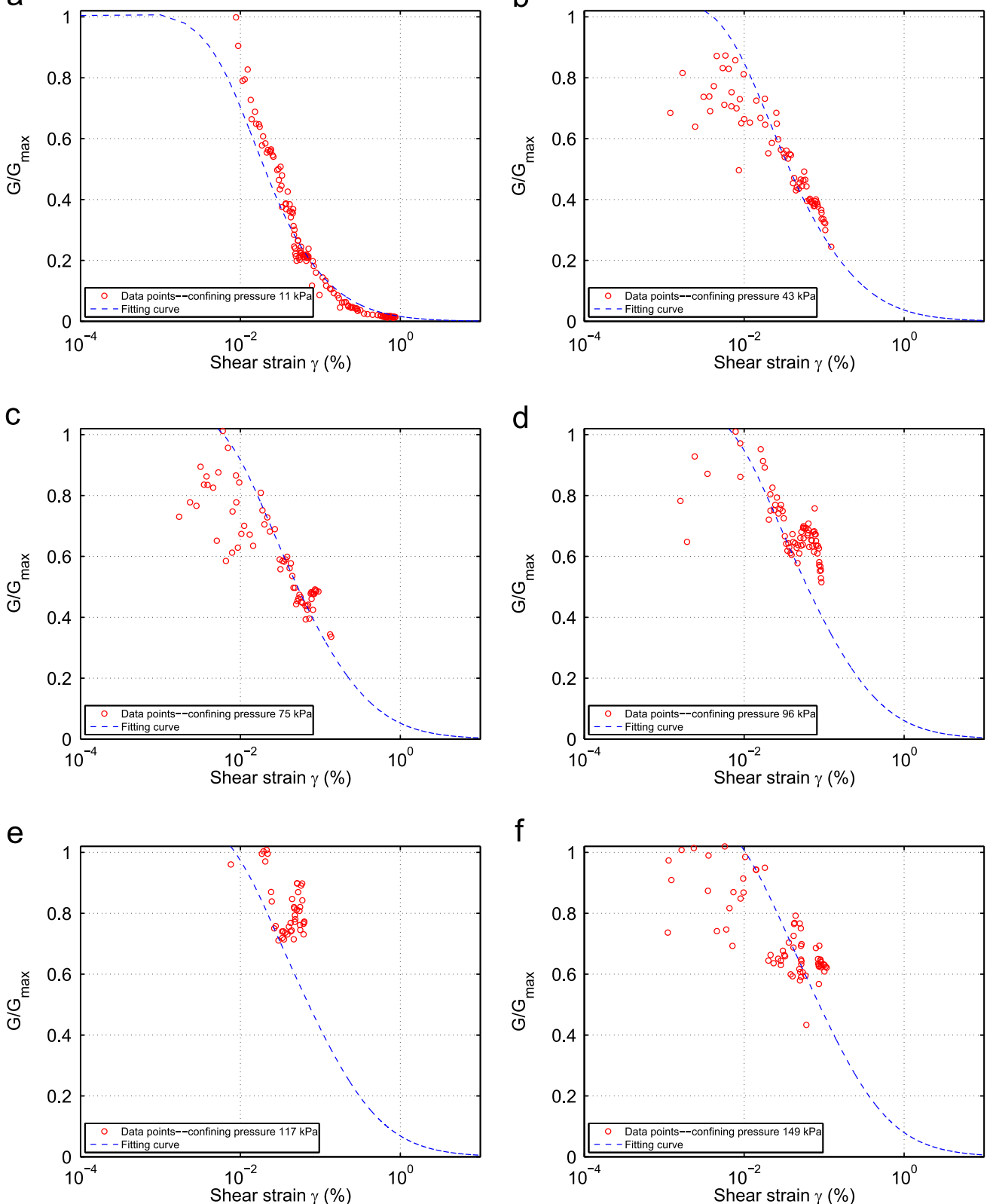

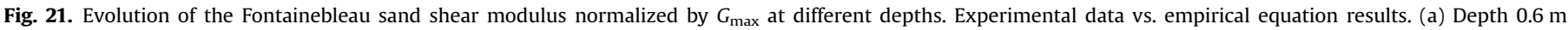

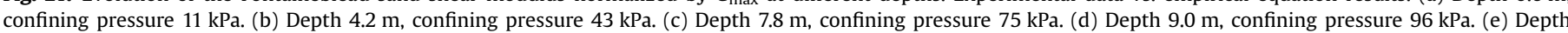
$12.6 \mathrm{~m}$, confining pressure $117 \mathrm{kPa}$. (f) Depth $16.0 \mathrm{~m}$, confining pressure $149 \mathrm{kPa}$ 


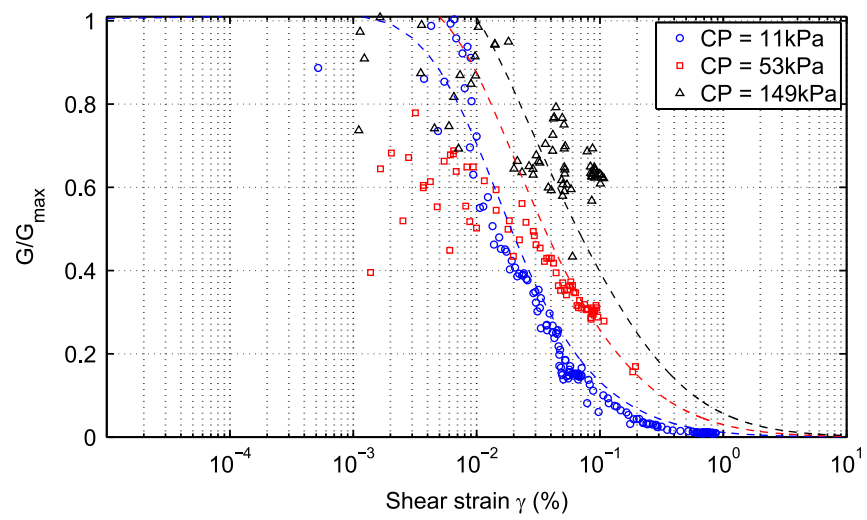

Fig. 22. Influence of the confining pressure $(\mathrm{CP})$ on the evolution of the Fontainebleau sand shear modulus. Experimental data vs. empirical equation results.

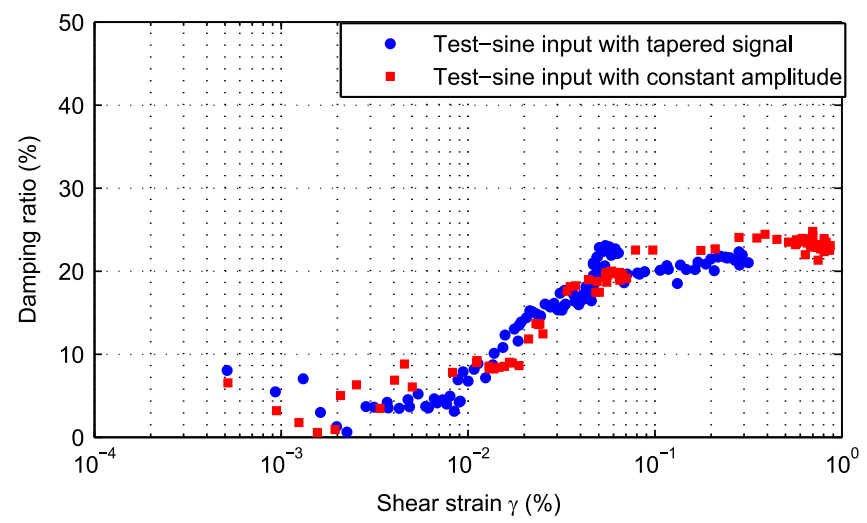

Fig. 23. Dynamic centrifuge tests: damping ratio vs. shear strain of the Fontainebleau sand at depth $1.8 \mathrm{~m}$ (confining pressure $21 \mathrm{kPa}$ ) - two types of loading signals.

$m(\gamma)-m_{0}=0.34\left[1-\tanh \left\{\ln \left(\frac{0.000556}{\gamma}\right)^{0.4}\right\}\right]$

The proposed equations for $K(\gamma)$ and $m(\gamma)-m_{0}$ combined with Eq. (11) capture the behavior of the Fontainebleau sand for different confining pressure levels. The influence of the confining pressure level (CP) is more highlighted in Fig. 22 (the precision of the processed data is enough to limit the dispersion of data points especially for high confining pressures). For high confining pressures the experimental data become more scattered with higher uncertainties. For the same shear strain level, the increase of confining pressure induces higher $G / G_{\max }$ ratio. Also, high confining pressures increase the elastic range of the sand.

\section{Damping ratio}

\subsection{A post-processing strategy to quantify the variation of the damping ratio with respect to the shear strain}

The post-processing method detailed in Section 4.2.4 is applied hereafter in order to obtain the average loops at different depths, Fig. 17. The equivalent damping ratio can then be estimated using Eq. (14), considering the dissipated energy $\Delta W$ and the maximum elastic energy $W$ stored at each loop, see Fig. 18:

$D=\frac{1}{2 \pi} \frac{\oint \tau \mathrm{d} \gamma}{0.25 \Delta \tau \Delta \gamma}=\frac{1}{2 \pi} \frac{\Delta W}{W}$

The application of the procedure to the dynamic centrifuge experimental data gives the results presented in Figs. 23 and 24.

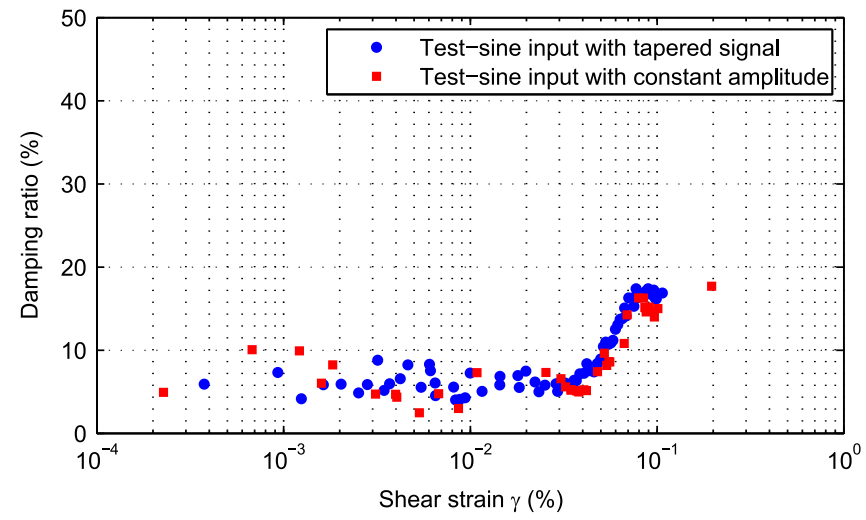

Fig. 24. Dynamic centrifuge tests: damping ratio vs. shear strain of the Fontainebleau sand at depth $5.4 \mathrm{~m}$ (confining pressure $53 \mathrm{kPa}$ )-two types of loading signals.

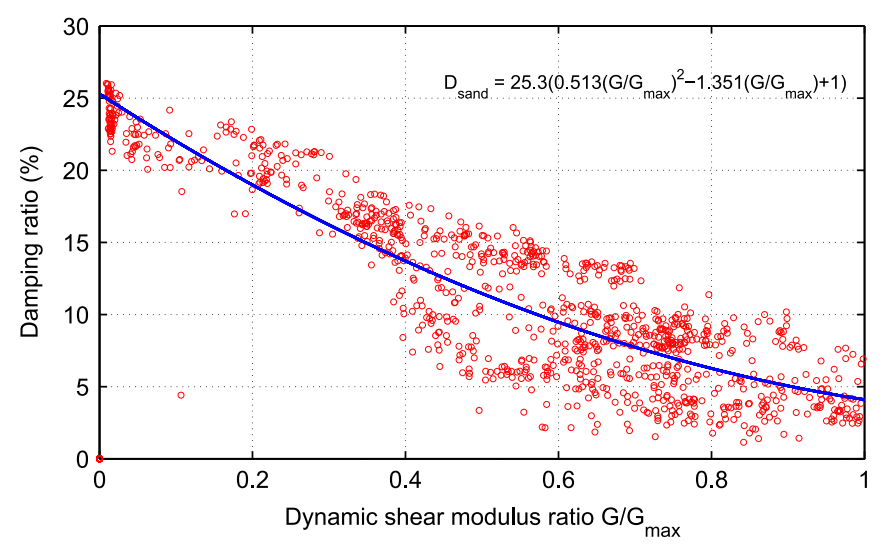

Fig. 25. Relationship between dynamic shear modulus and damping ratio.

Although results present a higher dispersion at low strain level, the damping value is estimated to be around 5\%. In other words, even at small strain level there is a certain energy dissipation.

\subsection{Empirical equation}

Hardin and Drnevich [20] and Tatsuoka et al. [23] proposed a formula where the damping ratio $D$ is expressed as a function of $G / G_{\text {max }}$, see Eq. (15). Ishibashi and Zhang [1] extended its application for high plastic soils introducing the influence of the plastic index PI.

For the case of the (dry) Fontainebleau sand used in the dynamic centrifuge tests, the expression takes the form of Eq. (16) after the appropriate fitting (damping is expressed as percentage (\%))

$D=f\left(\frac{G}{G_{\max }}\right) \Rightarrow$

$D=25.3\left\{0.513\left(\frac{G}{G_{\max }}\right)^{2}-1.351\left(\frac{G}{G_{\max }}\right)+1\right\}$

The fitting curve of the damping ratio is plotted together with the data points from all the 14 sand layers for confining pressures ranging from 11 to $149 \mathrm{kPa}$ in Fig. 25. It is found that the damping ratio increases with the reduction of the shear modulus. This type of graph gives us the possibility to quantify the damping ratio directly from $G / G_{\max }$ without plotting the damping vs. shear strain relationships. One can see that when $G / G_{\max }$ reaches its maximum value 1 , the damping ratio is about $4.1 \%$. This is in accordance with 
a

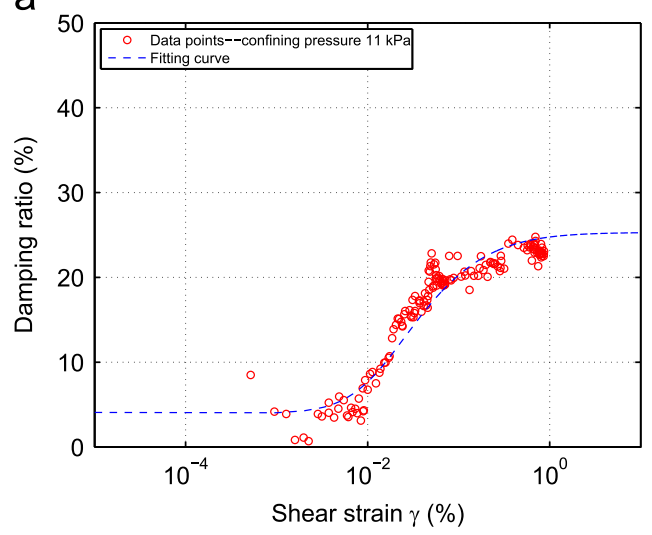

C

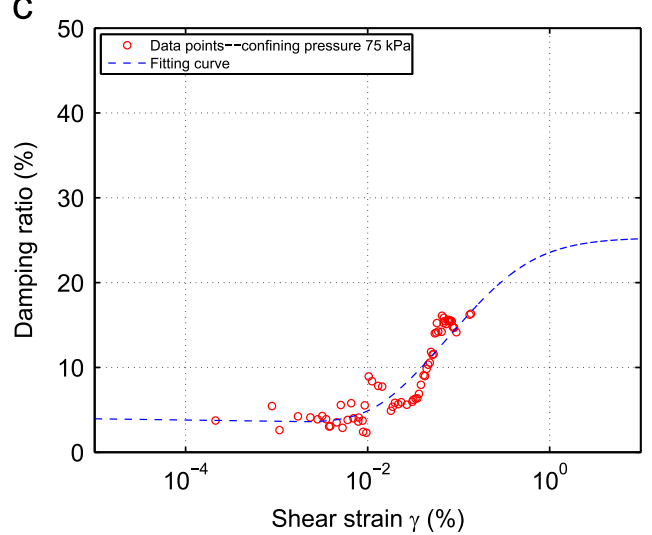

e

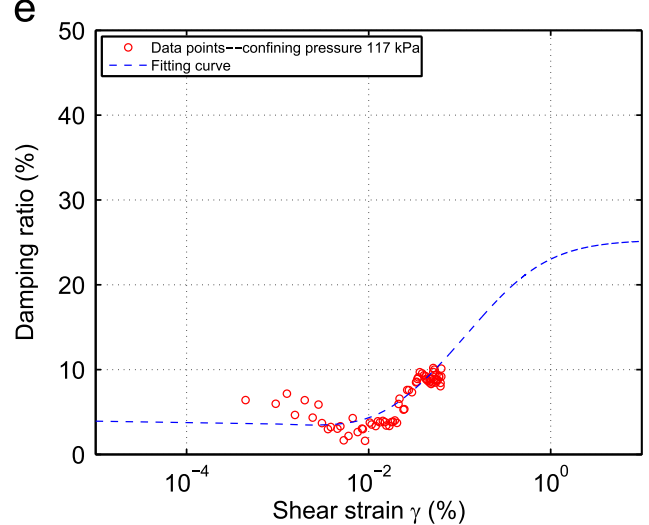

b

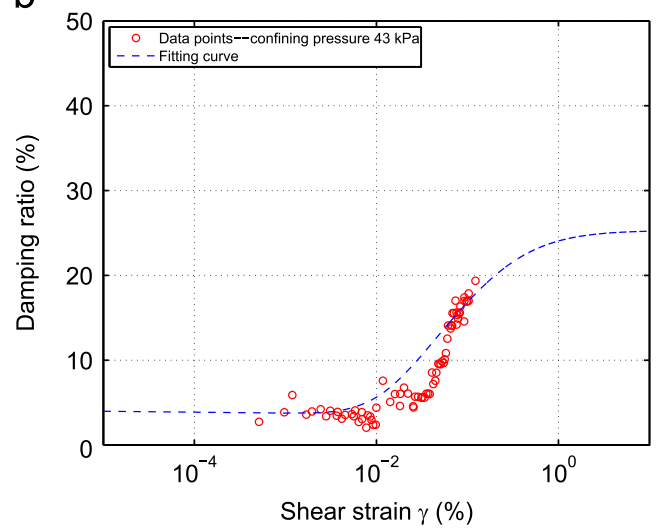

d

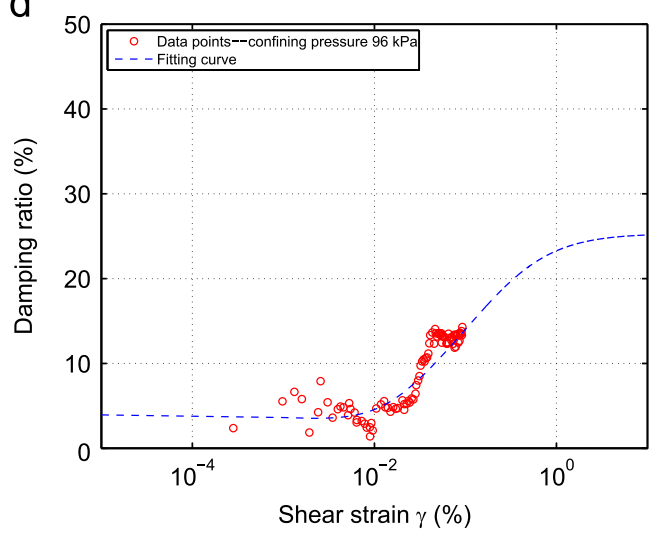

f

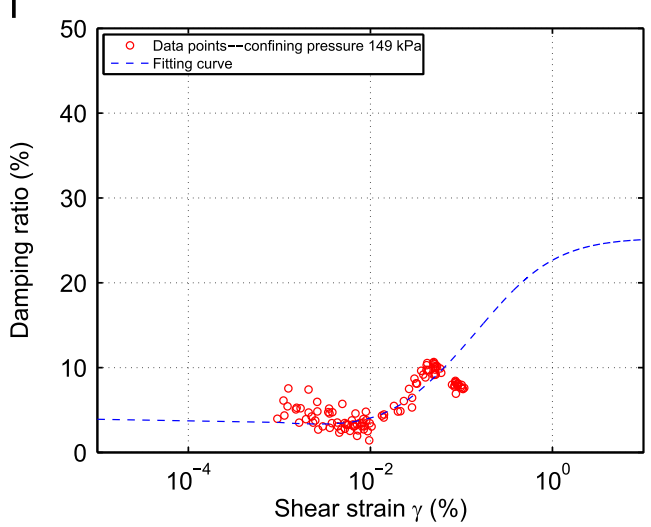

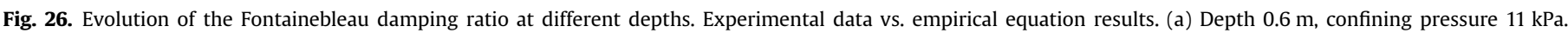

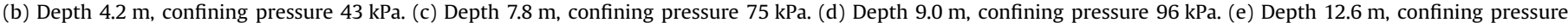
$117 \mathrm{kPa}$. (f) Depth $16.0 \mathrm{~m}$, confining pressure $149 \mathrm{kPa}$.

the results of Lanzo and Vucetic [24] that even at small strain levels, there exists some energy dissipation. Using Eq. (16), the damping ratio at different depths (confining pressures) with respect to the shear strain is plotted in Fig. 26. The influence of the confining pressure on the damping ratio is obvious. For the same shear strain, low pressure confined sand has a larger damping ratio, see Fig. 27.

\section{Conclusions}

In this paper, dynamic centrifuge tests based on free field conditions were performed in order to identify the
Fontainebleau sand properties. A large number of sensors was used to capture the response of the centrifuge model. A postprocessing strategy was proposed (with less dispersion compared to previous studies) based on the definition of average loops and the evolution of the shear modulus and the damping ratio was quantified. Empirical equations from the literature were validated and specific regressed numerical values are proposed for the Fontainebleau sand. It is found that confining pressure has an important influence on both the shear modulus evolution and the damping ratio. A low pressure confined sand tends to have a larger damping ratio and a greater shear modulus reduction. The high confining pressure tends to enlarge the elastic range of sand. 


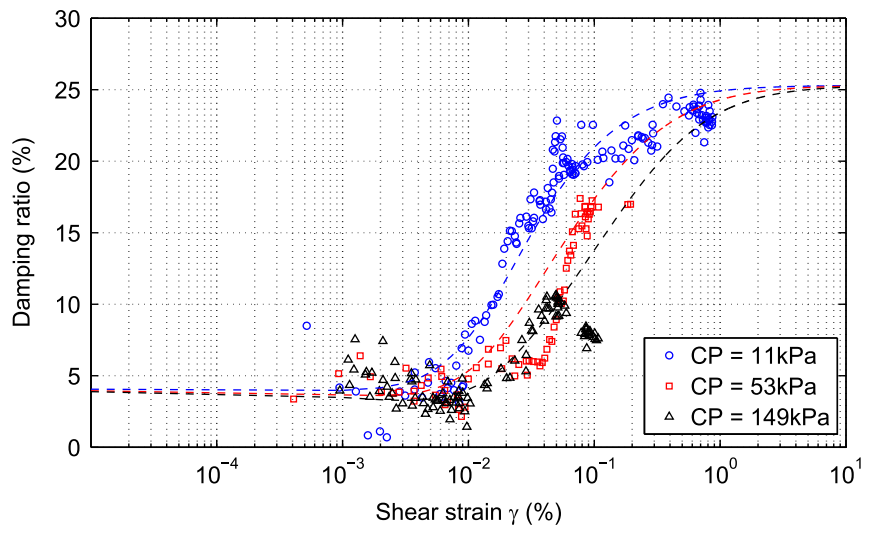

Fig. 27. Influence of the confining pressure (CP) on the evolution of the damping ratio of the Fontainebleau sand. Experimental data vs. empirical equation results.

\section{Acknowledgments}

The financial support of IFSTTAR (Institut français des sciences et technologies des transports, de l'aménagement et des réseaux) and of the Région Pays de la Loire is gratefully acknowledged. The authors would like also to thank the valuable support and help of the technical staff of the IFSTTAR centrifuge team.

\section{References}

[1] Ishibashi I, Zhang X. Unified dynamic shear moduli and damping ratios of sand and clay. Soils and Foundations 1993;33(1):182-91.

[2] Assimaki D, Li W, Kalos A. A wavelet-based seismogram inversion algorithm for the in situ characterization of nonlinear soil behavior. Pure and Applied Geophysics 2010;168(10):1669-91, http://dx.doi.org/10.1007/s00024-0100198-6.

[3] Brennan AJ, Thusyanthan NI, Madabhushi SPG. Evaluation of shear modulus and damping in dynamic centrifuge tests. Journal of Geotechnical and Geoenvironmental Engineering 2005;131(12):1488-97.

[4] Pitilakis K, Kirtas E, Sextos A, Bolton M. Validation by centrifuge testing of numerical simulations for soil-foundation-structure systems. In: 13th world conference on earthquake engineering, no. 2772, Vancouver, Canada, 2004.

[5] Zeghal M, Elgamal A. Analysis of site liquefaction using earthquake records. Journal of Geotechnical Engineering 1994;120(6):996-1017, http://dx.doi.org/ 10.1061/(ASCE)0733-9410(1994)120:6(996).

[6] Elgamal A, Yang Z, Lai T, Kutter BL, Wilson DW. Dynamic response of saturated dense sand in laminated centrifuge container. Journal of Geotechnical and Geoenvironmental Engineering 2005;131(5):598-609.
[7] Conti R, Viggiani GMB. Evaluation of soil dynamic properties in centrifuge tests. Journal of Geotechnical and Geoenvironmental Engineering 2012;138 (7):850-9, http://dx.doi.org/10.1061/(ASCE)GT.1943-5606.0000659.

[8] Chazelas JL, Escoffier S, Garnier J, Thorel L, Rault G. Original technologies for proven performances for the new LCPC earthquake simulator. Bulletin of Earthquake Engineering 2008;6(4):723-8, http://dx.doi.org/10.1007/s10518008-9096-z.

[9] Schofield A, Zeng X. Design and performance of an equivalent-shear-beam container for earthquake centrifuge modelling. Géotechnique 1996;46 (1):83-102.

[10] Teymur B, Madabhushi SPG. Experimental study of boundary effects in dynamic centrifuge modelling. Géotechnique 2003;53(7):655-63.

[11] Delfosse-Ribay E, Djeran-Maigre I, Cabrillac R, Gouvenot D. Shear modulus and damping ratio of grouted sand. Soil Dynamics and Earthquake Engineering 2004;24(6):461-71, http://dx.doi.org/10.1016/j.soildyn.2004.02.004.

[12] Seed $H$, Idriss I. Soil moduli and damping factors for dynamic response analyses. Technical Report, University of California, Berkeley, California, 1970.

[13] Hardin BO, Richart FEJ. Elastic wave velocities in granular soils. Journal of Soil Mechanics and Foundations Divisions: Proceedings of the American Society of Civil Engineers 1963:89(SM1):33-65.

[14] Iwasaki T, Tatsouka F, Takagi Y. Shear moduli of sands under cyclic torsional shear loading. Soils and Foundations 1978;18(1):39-56.

[15] Drnevich BO, Hardin VP. Shear modulus and damping in soils: design equations and curves. Journal of the Soil Mechanics and Foundations Division 1972;98:667-92.

[16] Gaudin C. Détermination de l'état de contrainte geostatique des massifs sableux centrifugés par des essais pénétrométriques. Raport de DEA de l'école Centrale de Nantes et du Laboratoire Central de Ponts et Chaussées de Nantes, 1999, p. 124.

[17] Wilson JMR, Bolton MD. Discussion: an experimental and theoretical comparison between static and dynamic torsional soil tests. Géotechnique 1990;40 (4):659-64, http://dx.doi.org/10.1680/geot.1990.40.4.659.

[18] Kramer SL. Geotechnical earthquake engineering. New Jersey: Prentice Hall; 1996.

[19] Wichtmann T, Niemunis A, Triantafyllidis T. Strain accumulation in sand due to cyclic loading: drained cyclic tests with triaxial extension. Soil Dynamics and Earthquake Engineering 2007;27:42-8, http://dx.doi.org/10.1016/j. soildyn.2006.04.001.

[20] Hardin B, Drnevich V, Wang J, Sams C. Resonant column testing at pressures up to $3.5 \mathrm{Mpa}$ (500 psi). Dynamic Geotechnical Testing II ASTM STP 1994:1:222-33.

[21] Kokusho T. The Japanese Geotechnical Society NII-electronic library service. Soils and Foundations 1980;20(2):45-60.

[22] Ishibashi I. Discussion of effect of soil plasticity on cyclic response by $\mathrm{M}$. Vucetic and R. Dobry. Journal of Geotechnical Engineering 1992;118(5):830-2.

[23] Tatsuoka F, Iwasaki T, Takagi Y. Hysteretic damping of sands under cyclic loading and its relation to shear modulus. Soils and Foundations 1978;18 (2):25-40.

[24] Lanzo G, Vucetic M. Effect of soil plasticity on damping ratio at small cyclic strains. Soils and Foundations 1999;39(4):131-41.

[25] Irina A. Caractérisationi dynamique de sables de référence en laboratoire Application à la réponse sismique de massifs sableux en centrifugeuse. Ph.d Thése de Institue Français des Sciences et Technologies des Transports, de l'Aménagement et des Réseaux - IFSTTAR, Laboratoire NAVIER - Géotechnique (CERMES). 